\title{
The process parameters effect of ovality in cross wedge rolling for hollow valve without mandril
}

\author{
Hongchao Ji', Jinping Liu'ª, Baoyu Wang ${ }^{1}$, Jianguo Lin² ${ }^{2}$ Xuefeng Tang ${ }^{1}$ \\ ${ }^{1}$ School of Mechanical Engineering, University of Science and Technology Beijing, Beijing 100083, China \\ ${ }^{2}$ Department of Mechanical Engineering, Imperial College London, London SW7 2AZ, UK
}

\begin{abstract}
This paper presents the experimental and numerical results of the effect process parameters on ovality in cross wedge rolling (CWR) for hollow engine valve without mandrel. Numerical simulation model for ovality was established by means of the rigid-plastic finite element modeling (FEM) method for hollow engine valve. The experiments and numerical analyses suggest that the following parameters represent the best conditions for CWR of hollow engine valve: $30^{\circ}-34^{\circ}$ for the forming angle $(\alpha), 5^{\circ}-7^{\circ}$ for the stretching angle $(\beta), 0.2-0.3 \mathrm{~mm}$ for the mold void width $(L)$, and $65 \%-70 \%$ for the area reduction $(\Psi)$.
\end{abstract}

Key words: Hollow engine valve; Ovality; Cross wedge rolling; Experiment; Finite element modeling

\section{Introduction}

With the development of automotive technology, more and more hollow engine valves are needed. The CWR process is a new metal forming technique for producing hollow engine valve[1]. Many studies have been carried out on hollow parts by experimental, analytical and simulation methods. Z.Pater [2-4] et al studied the three-roll CWR without mandrel forming hollow shafts, and the parameters on CWR process were analyzed using numerical simulation. In addition, the plate wedge rolling of hollow shafts were comparatively analyzed. M.Lovell [5-6] et al studied the CWR theory and technology on the hollow shaft parts. Experiments and FE simulation was carried out to study the instable conditions on CWR process.

Ovality defects significantly affect the mechanical properties of hollow shaft parts and yield additional stresses under the action of internal pressure, in which the former causes uneven and hollow shafts. Compressive strength decreases under external pressure, thereby reduces the stability of the hollow engine valve. A degree of ovality is observed in hollow shaft parts. Installation of mechanical vibrations is caused by equipment or components, which seriously affects the use of shaft parts. In this paper, we used CWR technology to produce hollow engine valve. FEM of the CWR process was performed using the software Deform-3D. Experimental and FEM were used to study the ovality of hollow engine valve in different parameters.

\section{Experimental details}

Experimental tests on the CWR process were conducted using the $\mathrm{H} 500$ mill available at the University of Science and Technology Beijing in Beijing, China. The simplified model of cross wedge rolling is shown in Figure. 1a. A picture of the H500 mill is shown in Figure.1b. During the research, the workpieces of 4Cr9Si2 were heated to $1150^{\circ} \mathrm{C}$ and formed. The experimental process was follows:

(1) A GB4025B horizontal metal band saw and a hollow steel rod were used. The rod is $25 \mathrm{~mm}$ in diameter and was cut to $100 \mathrm{~mm}$ in length.

(2) Workpieces were heated in the tube furnace for $30 \mathrm{~min}$ at a suitable temperature to conserve electricity and evenly distribute the heat within the pieces. The procedure was based on previous cross-valve wedge rolling experiments.

(3) The workpieces were uniformly heated and processed in H500 mill. Subsequently, the workpieces were cooled after rolling to ordinary temperature.

(4) The formation and quality of rolling after cooling were observed and recorded.

\footnotetext{
${ }^{a}$ Corresponding author: Jinping Liu E-mail: liujp@ustb.edu.cn
} 

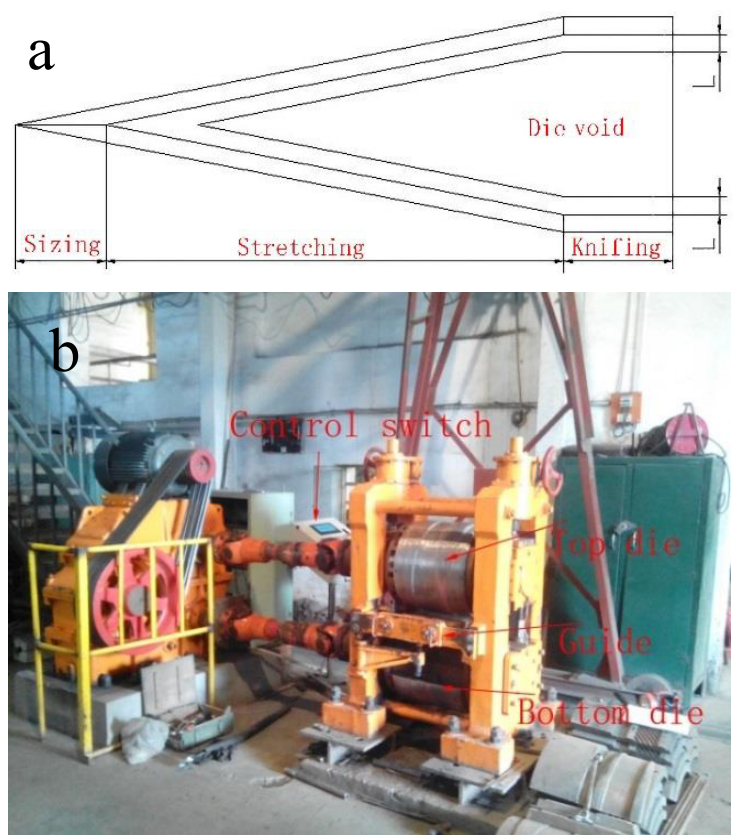

Figure.1 (a)Die for engine valve (b)The H500 mill

\section{Finite element modeling}

FEM of CWR was performed using the deform. Figure. 2 shows the geometrical model of the analyzed process. The material accuracy of constitutive models directly determined the accuracy of the simulation results. No flow stress of $4 \mathrm{Cr} 9 \mathrm{Si} 2$ alloys existed in the library of deform software. Hence, Gleeble-1500 thermal simulations for the alloys were characterized under different deformation conditions to analyze the behavior of thermal deformation. Actual stress-strain curves for a temperature range from $950^{\circ} \mathrm{C}$ to $1180{ }^{\circ} \mathrm{C}$ and strain rate values of $0.1,1,5$, and $10 \mathrm{~s}^{-1}$ were obtained. (Figure.3). Constitutive relationships were imported into the Deform-3D software to investigate the cooling process. Figure. 4 is the forming process of the rolled piece.

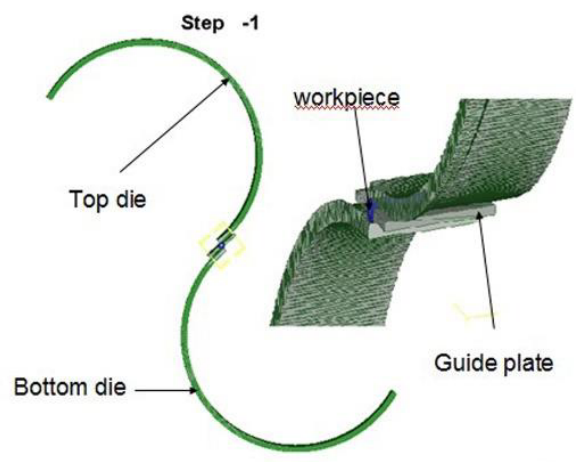

Figure.2 FEM model of cross wedge rolling (Deform-3D)

Friction coefficient $\mathrm{m}$ on the material-mold interface is constant. The friction force in the constant shear model is defined as follows:

$$
f_{\mathrm{s}}=m^{*} k
$$

where $f_{s}$ is the frictional stress and $\mathrm{k}$ is the shear yield stress. Eq. (1) indicates that friction is a function of $\mathrm{k}$ in the deforming body.
Table.1 illustrates the main rolling conditions and information of the workpieces.
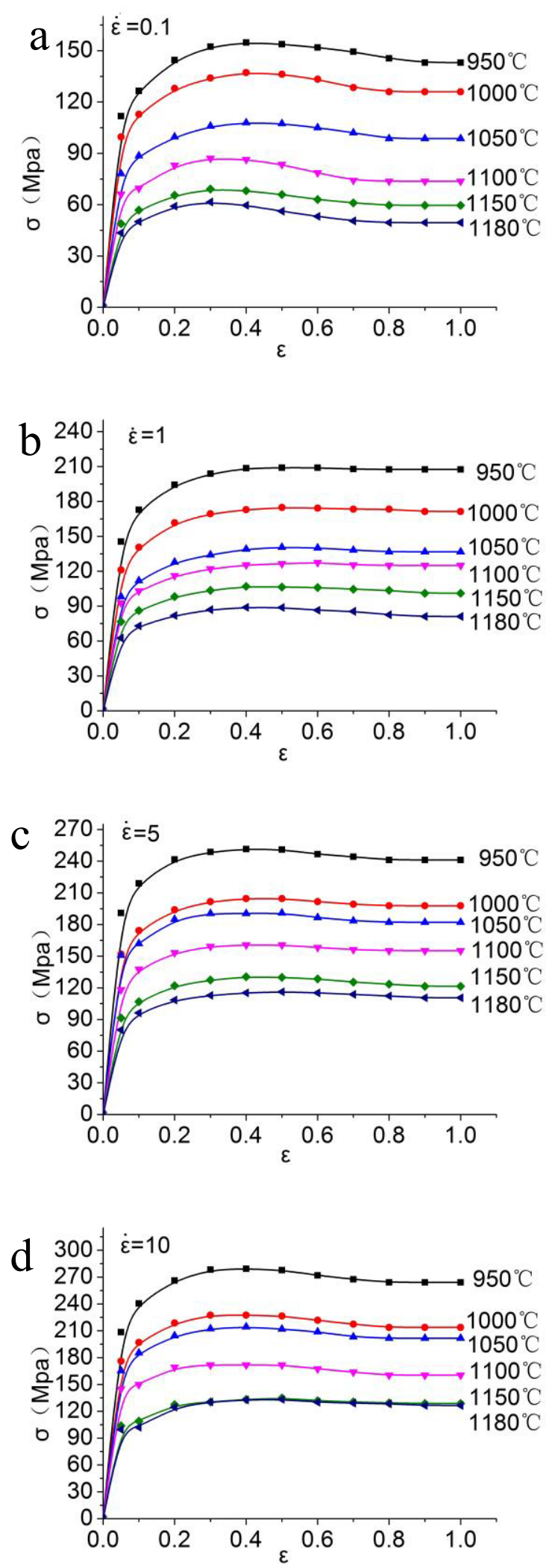

Figure.3 Flow curves of $4 \mathrm{Cr} 9 \mathrm{Si} 2$ at strain rates of (a) $0.1 \mathrm{~s}^{-1}$ (b) $1 \mathrm{~s}^{-1}(\mathrm{c}) 5 \mathrm{~s}^{-1}$ and (d) $10 \mathrm{~s}^{-1}$. 


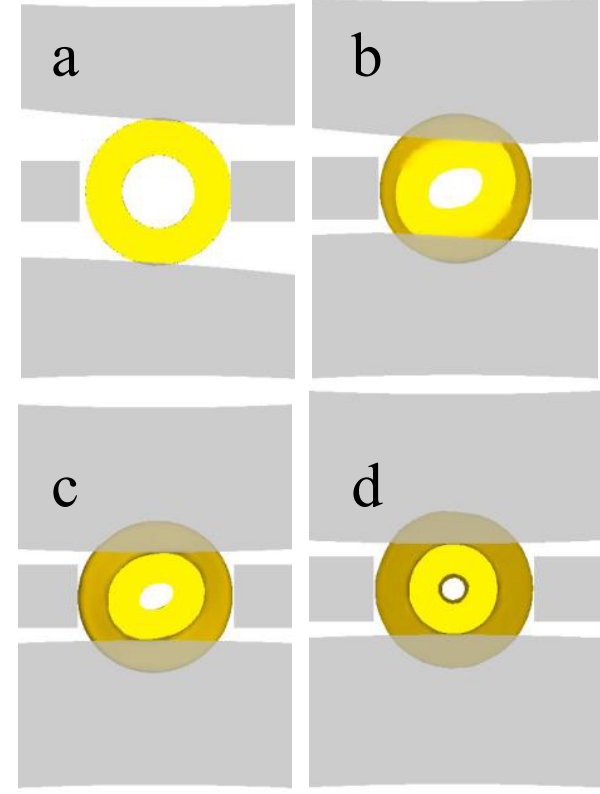

Figure.4 Forming process of the rolled piece Table.1 Parameter of cross wedge rolling simulation

\begin{tabular}{cc}
\hline Parameter & Value \\
\hline Speed of roll $(\mathrm{rpm})$ & 10 \\
Workpiece temperature $\left({ }^{\circ} \mathrm{C}\right)$ & 1,150 \\
Molds temperature $\left({ }^{\circ} \mathrm{C}\right)$ & 20 \\
Environment temperature $\left({ }^{\circ} \mathrm{C}\right)$ & 20 \\
Heat transfer coefficient $\left(\mathrm{N} / \mathrm{s} / \mathrm{mm} /{ }^{\circ} \mathrm{C}\right)$ & 40 \\
Convection coefficient $\left(\mathrm{N} / \mathrm{s} / \mathrm{mm} /{ }^{\circ} \mathrm{C}\right)$ & 0.02 \\
Friction factor $(\mathrm{m})$ & 0.9 \\
Mesh number for billet & 90000 \\
Mold material & $\mathrm{H} 3$ \\
Billet material & $4 \mathrm{Cr} 9 \mathrm{Si} 2$
\end{tabular}

The simulation is divided into four groups and the calculation parameters are shown in Table. 2 .

Table 2 main process parameters for simulation

\begin{tabular}{ccccc}
\hline $\begin{array}{c}\text { Ite } \\
\mathrm{m}\end{array}$ & $\begin{array}{c}\text { Forming } \\
\text { angle } \\
\alpha\left(^{\circ}\right)\end{array}$ & $\begin{array}{c}\text { Stretching } \\
\text { angle } \\
\beta\left({ }^{\circ}\right)\end{array}$ & $\begin{array}{c}\text { Die void } \\
\text { width } \\
L(\mathrm{~mm})\end{array}$ & $\begin{array}{c}\text { Area } \\
\text { reduction } \\
\psi(\%)\end{array}$ \\
\hline 1 & $\begin{array}{c}26,28,30,32, \\
34\end{array}$ & 6.5 & 0.25 & 67.89 \\
2 & 30 & $\begin{array}{c}4,6.5,7.5,8.5, \\
9.5\end{array}$ & 0.25 & 67.89 \\
3 & 30 & 6.5 & $0.20,0.25,0$. & 67.89 \\
& & & 30 & $30.56,40$. \\
4 & 30 & 6.5 & 0.25 & $\begin{array}{c}22, \\
51,59.89, \\
\end{array}$ \\
& & & & 67.89 \\
\hline
\end{tabular}

\section{Results and discussion}

Experimental results reveal that the hollow engine valve formed by CWR can be accurately pierced and rolled. Figure.5 illustrates the hollow engine valve produced by CWR.
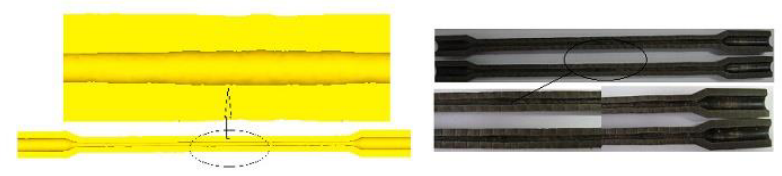

Figure.5 FEM and experimental test samples

Given the maximum and minimum inner diameter $D_{\max }$ and $D_{\min }$, the bore ovality $\boldsymbol{e}$ is expressed as follows:

$$
e=\frac{2\left(D_{\max }-D_{\text {min }}\right)}{D_{\text {max }}+D_{\text {min }}} \times 100 \%
$$

From FEM of hollow engine valve, $\boldsymbol{e}$ was measured in the symmetrically center section of the roll. The ovality of hollow engine valve in different parameters was analyzed.

\subsection{Effects of forming angle}

The workpiece is bitten and rotated in the knifing zone. The model gradually shifts from the radial state to rolling state. The radial force is large, the radial flow of the metal rolling near the symmetry plane is relatively intense, and the axial flows relatively flat. Given the condition of axial flow, metal flows in the radial direction and results in a large radial force. Moreover, the axial force is relatively small and can easily be formed in the ovality-induced section of the wedge hole. Figure.6 shows the effect of $\boldsymbol{\alpha}$ on $\boldsymbol{e}$.

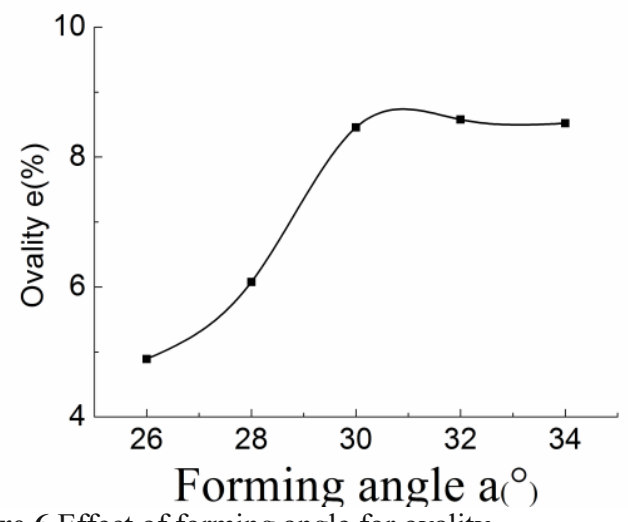

Figure.6 Effect of forming angle for ovality $\beta=6.5^{\circ}, L=0.25 \mathrm{~mm}, \Psi=67.89 \%, T=1150^{\circ} \mathrm{C}$

The turning point for the curve occurs at $\alpha=32^{\circ}$. The ovality reaches a maximum, but the curve is symmetrical oval near the surface of the workpiece position in the hole with increasing $\boldsymbol{\alpha}$.

Collected, comparison, and in-depth analysis of the radial and axial forces of rolling wedge segments were performed on deform software under different $\boldsymbol{\alpha}$ of the ovality to determine the effect of the law. Figure.7 indicate the temporal changes in the radial and axial forces of rolling wedge segments.

Figure.7 reveals that the rolling radial force increases with time in the wedge segments. On the other hand, the axial force initially increases with time and slowly reduces thereafter. Meanwhile, rolling subjected to axial force increases with $\boldsymbol{\alpha}$. The rolling radial force suffered before and after $0.35 \mathrm{~s}$ increase and decrease with increasing $\boldsymbol{\alpha}$, respectively. For rolling under different $\boldsymbol{\alpha}$ in 
the inner diameter of the wedge segments before $0.35 \mathrm{~s}$, the rolling force remains constant with time. However, the radial rolling force is generated with increasing $\boldsymbol{\alpha}$ because of rapid rolling by wedging effect. Hence, the angle formed by rolling at a large radial force is greater than that at a small radial force. The rolling force acts on the metal roll at an exactly symmetrical position near the surface, In addition, the increase in radial force increases $\boldsymbol{e}$ of the rolling hole within specific $\boldsymbol{\alpha}$ values. After $0.35 \mathrm{~s}$, the radial force decreases with $\boldsymbol{\alpha}$ and decreases $e$. The wedging segment bore the narrow ovality, but the rolling before $0.35 \mathrm{~s}$ exhibits a specific $\boldsymbol{e}$. Radial forces in different angles after 0.35 s reduces $\boldsymbol{e}$ in the inner hole. However, the effect on the nearby rolling plane of symmetry of the oval hole is limited.

The increase in axial force reduces $\boldsymbol{e}$ of the workpiece. In wedge segments, the axial force is significantly less than the radial force. Moreover, the magnitude of the increase in radial force is greater than that of the axial force. By contrast, the axial force in the local time decreases with time; hence, the axial flow of the metal workpiece is relatively flat. Therefore, increased $\boldsymbol{\alpha}$ increases the rolling plane of symmetry near the location of hole ovality in wedging segments. The radial force in the rolling region is relatively stable.
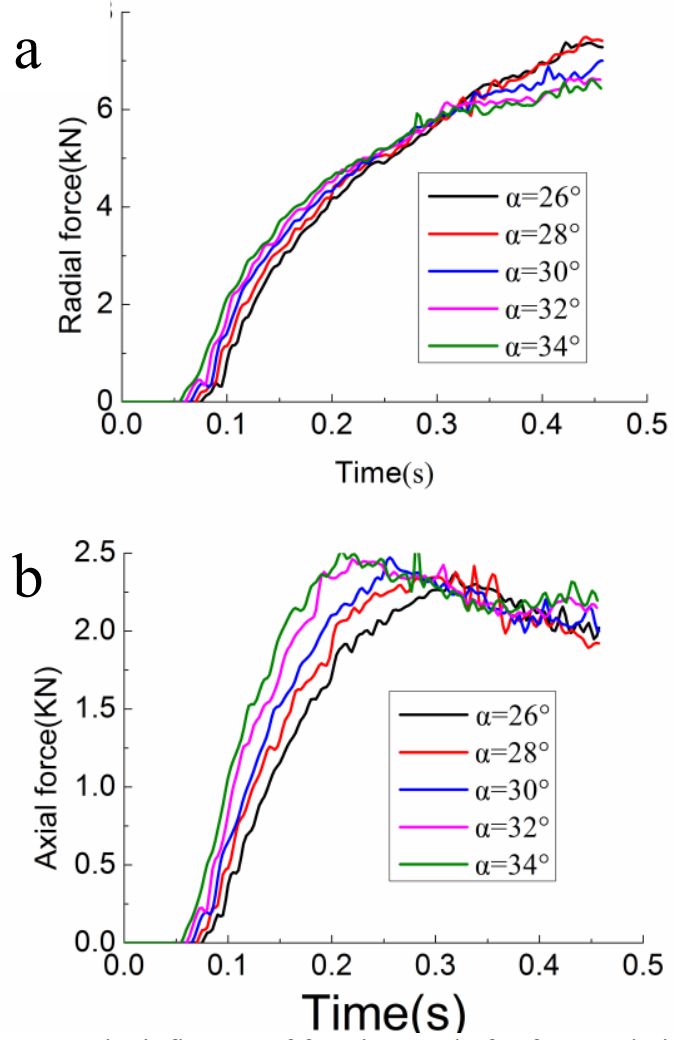

Figure.7 The influence of forming angle for force at knifing (a) radial force (b) axial force

\subsection{Effect of stretching angle}

The $\boldsymbol{e}$ curve (Figure.8) reveals that the hole ovality near the position of the rolling symmetry gradually increases with $\boldsymbol{\beta}$.

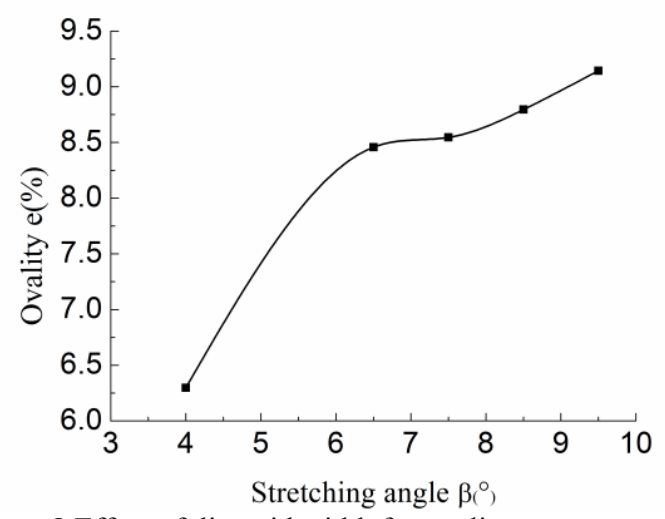

Figure.8 Effect of die void width for ovality $\alpha=30^{\circ}, L=0.25 \mathrm{~mm}, \Psi=67.89 \%, T=1150^{\circ} \mathrm{C}$

Figure. 9 show the rolling radial and axial forces in the wedging segment with time. The radial force in the wedge segment increases with time and $\boldsymbol{\beta}$. Meanwhile, the axial force in the wedging segment initially increases with time and slightly elevates thereafter. For the increasing stage, the axial force increases with $\boldsymbol{\beta}$; for gentle stages, the force decreases with increasing $\boldsymbol{\beta}$.

Increased $\boldsymbol{\beta}$ increases the magnitude of metal flow of metal in the rolling deformation zone. Moreover, the magnitude of axial compression and the rolling resistance to the extension increase. The oppositely directed friction to metal flow increases; however, the axial metal flow weakens and the axial force gradually reduces in gentle stages. Rolling metal flow and the contact area of the deformed shaft radially increases. The resultant radial force increases, which emphasizes the behavior of $\boldsymbol{e}$. The radial force is relatively stable and the roundness of the formation zone in the rolling forming region.
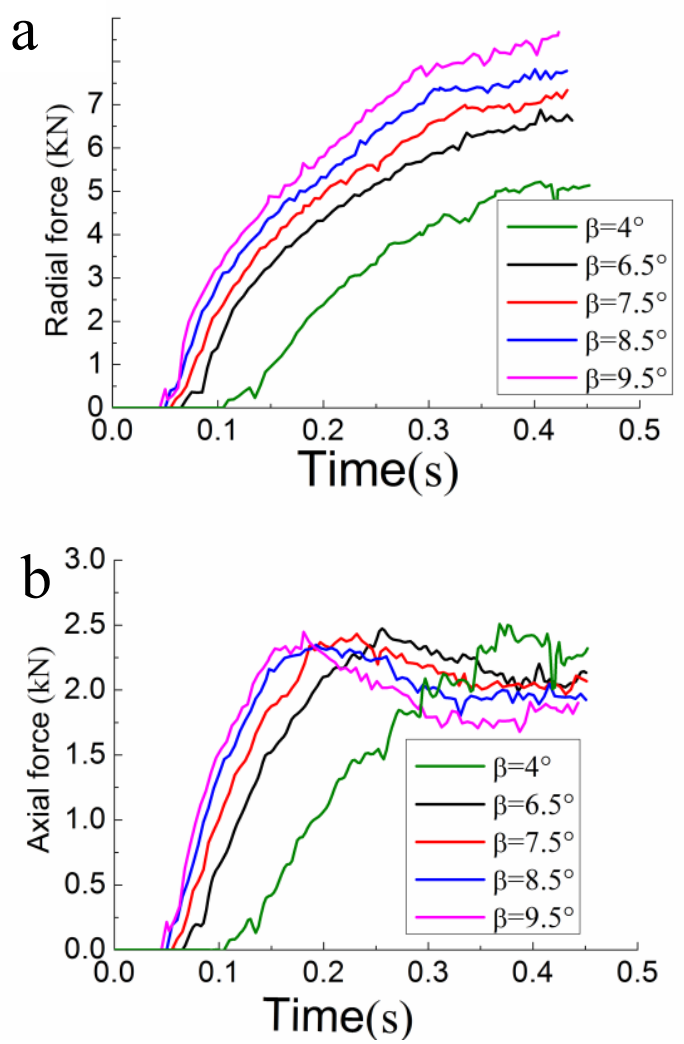

Figure.9 The influence of stretching angle for force at knifing 
(a) radial force (b) axial force

\subsection{Effect of die void width}

Figure.10 shows that e near the rolling location slowly increases with $\boldsymbol{L}$. Figure. 11 represent the temporal variations in radial and axial forces in the rolling wedging segment. The radial force increases with time; the axial force initially increases with time and decreases thereafter. For various $\boldsymbol{L}$, rolling radial and axial forces in the wedge segment remain constant with time. Therefore, in the wedge segments, force parameters under various $\boldsymbol{L}$ do not primarily affect $\boldsymbol{e}$ near the location of symmetry after rolling.

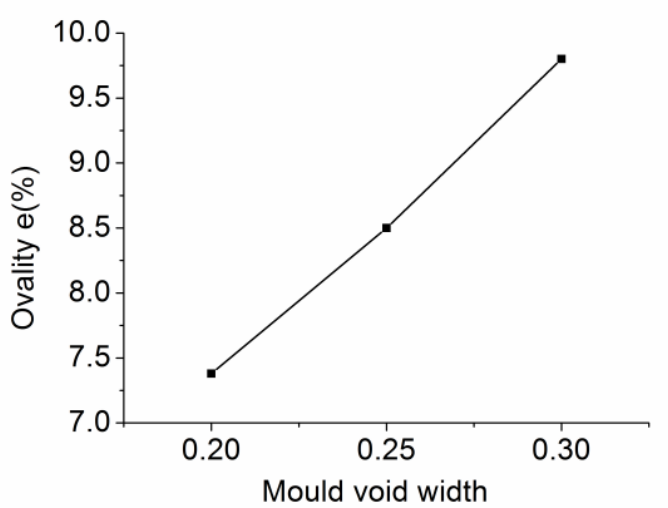

Figure.10 Effect of die void width for ovality $\alpha=30^{\circ}, \beta=6.5, \Psi=67.89 \%, T=1150^{\circ} \mathrm{C}$

During wedge deformation, $\boldsymbol{L}$ does not affect $\boldsymbol{e}$ near the symmetry location; however, $\boldsymbol{e}$ in this part influences the mold wedge segment. The rolling environment is highly stable after stretching deformation. $\boldsymbol{e}$ in the hole near the position of rolling symmetry plane is maintained. However, $\boldsymbol{e}$ on the position of the rolling plane of symmetry is affected because of changes in $\boldsymbol{L}$. When the metal enters the void position of the stretching segment, it flows from the pressure of the large area to that of the small area. The void range increases with decreasing $\boldsymbol{L}$, which is unfavorable to axial efflux of the metal. A portion of the metal has refluxed to the rolling plane of symmetry. After rolling to the location near the symmetry plane, a portion of the metal refluxes to the small radial flow rather than the lateral flow. Hence, the hole is gradually rounded and $\boldsymbol{e}$ decreases at the original location near the rolling plane of symmetry. While refluxing occurs in some metals, $\boldsymbol{e}$ slightly varies with $\boldsymbol{L}$. The result explains the increase in $\boldsymbol{e}$ near the location of the rolling plane of symmetry with increasing $\boldsymbol{L}$. Stretched formation region relatively stabilizes the radial force and increases the probability of bore round holes in this region.
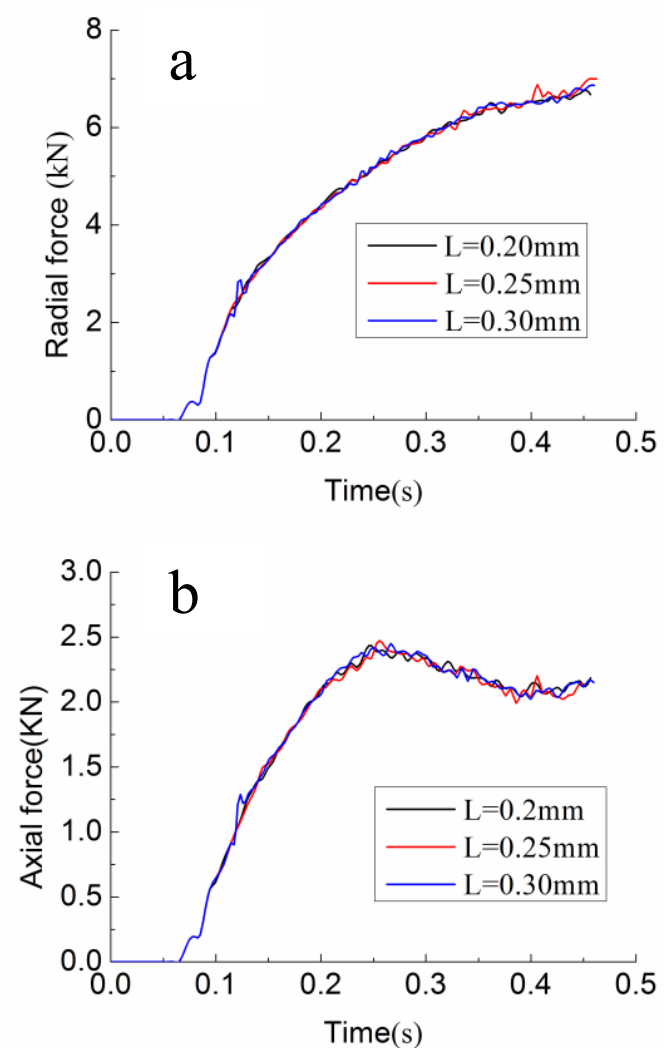

Figure.11 The influence of die void width for force at knifing (a) radial force (b) axial force

\subsection{Effect of area reduction}

$\boldsymbol{e}$ near the position of the symmetry plane initially increases then decreases thereafter with increasing section shrinkage (Figure.12). The reduction rate is $41.22 \%$, which is the turning point.

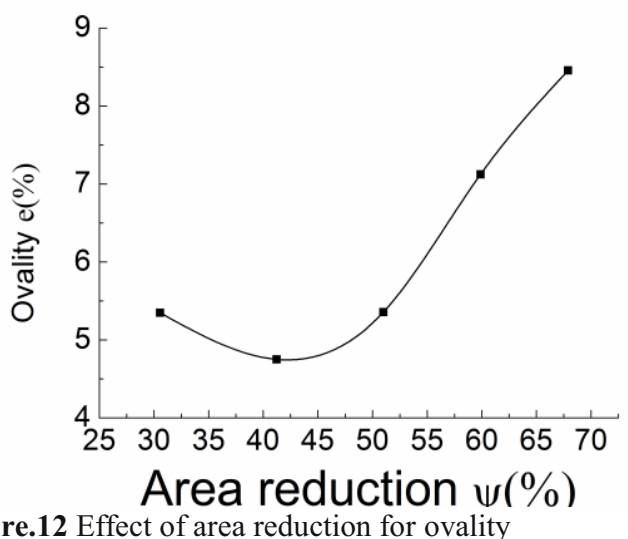

Figure.12 Effect of area reduction for ovality $\alpha=30^{\circ}, \beta=6.5^{\circ}, L=0.25 \mathrm{~mm}, T=1150^{\circ} \mathrm{C}$

Figure. 13 show that rolling radial force in the wedge segment increases with time; the axial force initially increases and then slowly decreases with time. The high extent of reduction and small rolling radial force increase the rolling axial force.

After mold wedge rolling with increasing mold amount relative to the axial exclusion, rolling increases, axial force increases, radial flow decreases, and radial force reduces.

Increased axial force and reduced radial force 
decreases $\boldsymbol{e}$. However, $\boldsymbol{e}$ constantly decreases with increasing cross-sectional shrinkage rate between $30.56 \%$ and $41.22 \%$. Given the increase in section shrinkage rate between $41.22 \%$ and $67.89 \%$, the thinning rate of the rolling wall thinning increases, the mold roll surface is close to the inner surface of the rolling, and the radial mobility of the metal to the mold increases. Radial shrinkage forces affect the results of the accuracy of the hole shape in the workpiece are highly significant. Although the radial force is reduced or slightly decreased, variation in $\boldsymbol{e}$ are large and the degree of the ovality increases. The radial force being stretched in rolling forming region is relatively stable, and roundness in the formation zone increases.
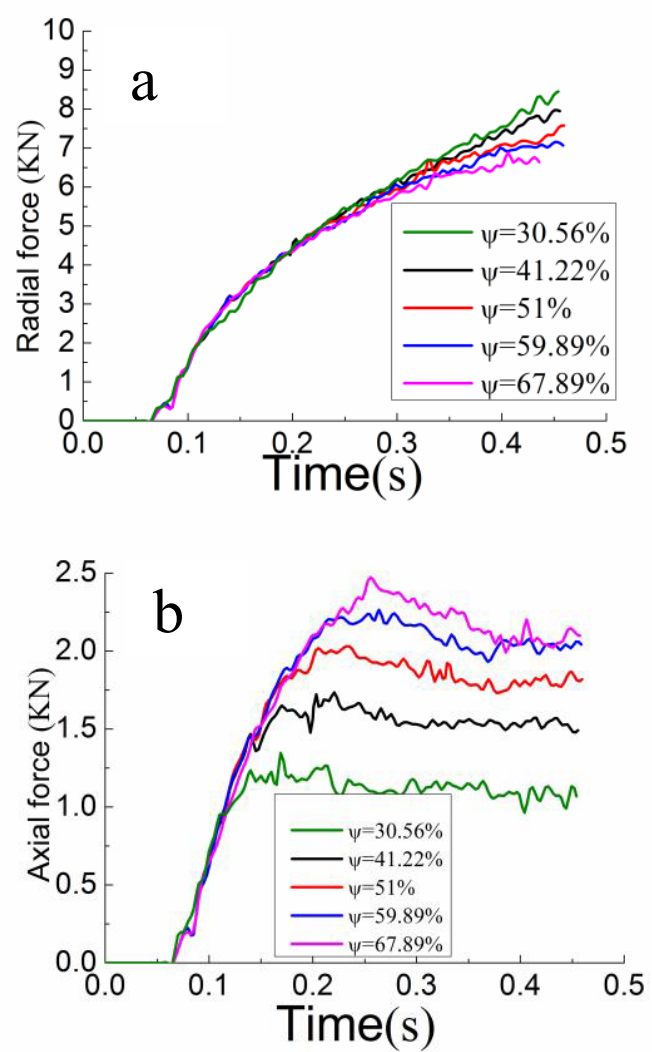

Figure.13 The influence of area reduction for force at knifing (a) radial force (b) axial force

\section{Summary and conclusions}

The following conclusions were drawn from conducted experiments and numerical analyses:

(1) $\boldsymbol{e}$ in the cross-section near the symmetry location increases with $\alpha$ of the mold from $26^{\circ}$ to $34^{\circ}$ after hollow rolling mill.

(2) Given the increase in $\boldsymbol{\beta}$ of the mold from $4^{\circ}$ to $9.5^{\circ}, \boldsymbol{e}$ in the cross-section near the symmetry location increases after hollow rolling mill.

(3) Given the increase in $\boldsymbol{L}$ from $20 \mathrm{~mm}$ to $30 \mathrm{~mm}, \boldsymbol{e}$ in the cross-section near the symmetry location around the inner rolling surface slightly increases after hollow rolling mill.

(4) Increased area reduction rate from $30.56 \%$ to $67.89 \%$ initially increases $\boldsymbol{e}$ in the cross-section near the position of the rolling symmetry plane and then decreases.
The turning point occurs at an area reduction rate of $41.22 \%$.

(5) We determine the following rolling process parameters given their effects on $\boldsymbol{e}$ as follows: $\boldsymbol{\alpha}=30^{\circ}$ $34^{\circ} ; \boldsymbol{\beta}=5-7^{\circ} ; \boldsymbol{L}=20 \mathrm{~mm}-30 \mathrm{~mm}$; area reduction $65 \%-$ $70 \%$. $\boldsymbol{e}$ significantly improves in line with target product requirements. Hence, CWR of hollow engine valve is feasible.

\section{Acknowledgement}

This work is supported by YangFan Innovative \& Entepreneurial Research Team Project (No.201312G02).

\section{References}

1.H. Ji, J. Liu, B. Wang, Z. Zheng, J. Huang, Z. Hu, Cross-wedge rolling of a 4Cr9Si2 hollow valve: explorative experiment and finite element simulation, Int. J. Adv. Manuf. Technol. 77 (2015) 15-26.

2.J. Bartnicki, Z. Pater, The influence of tool geometry on the CWR process of hollowed shafts, STEEL-GRIPS J. Steel. Relat. Mater. (2004) 2 103-107, Suppl. metal forming.

3.Z. Pater, A. Gontarz, J. Tomczak, T. Bulzak, Producing hollow drive shafts by rotary compression, Arch. Civ. Mech. Eng. (2015). DOI: 10.1016/j.acme.2014.10.002

4.J. Tomczak, T. Bulzak, Z. Pater, The Effect of Billet Wall Thickness on the Rotary Compression Process for Hollow Parts, Strojniški vestnik - J. Mech. Eng. 61 (2015) 149-156.

5.S. Urankar, M. Lovell, C. Morrow, Q. Li, K. Kawada, Establishment of failure conditions for the cross-wedge rolling of hollow shafts, J. Mater. Process. Technol. 177 (2006) 545-549.

6. Q. Li, M. Lovell, The establishment of a failure criterion in cross wedge rolling. Int. J. Adv. Manuf. Technol. (2004) 24:180-189. 